\title{
Autores e editores de compêndios e livros de leitura (1810-1910)
}

\author{
Circe Maria Fernandes Bittencourt
}

Universidade de São Paulo

\section{Resumo}

Este artigo apresenta reflexões sobre o problema da autoria do livro didático. 0 papel do autor do livro didático tem sido um tema polêmico por sua ambigüidade em relação a seus direitos e suas responsabilidades. 0 livro didático oferece retornos financeiros consideráveis para editores e autores, e esta condição implica envolvimentos mais complexos e tensos. 0 artigo procura, nessa perspectiva, traçar o perfil dos primeiros autores de livros didáticos brasileiros, no período de 1810 a 1910, com o objetivo de caracterizar o processo de intervenções de diferentes sujeitos nessa produção. As características da produção do livro didático como texto submetido aos programas curriculares, dependente das autorizações do poder educacional e das formas de comercialização e circulação, são indicadas para mostrar quem foram os autores que aceitaram essas imposições. Apresenta as imposições para a confecção dos livros diante das mudanças do público ao qual é destinado. Inicialmente produzido para professores, o livro didático vai se tornando livro do aluno. Nesse processo os referenciais pedagógicos e o público escolar passaram a exigir cuidados com a linguagem e exige-se a constituição de novos "gêneros didáticos" para o nível elementar. 0 perfil do autor do livro didático transforma-se, assim como sua autonomia, acentuando as relações entre editor e autor.

\section{Palavras-chave}

Livro didático - Autoria - Editoras - Função-autor. 


\title{
Editors and authors of compendia and reading books (1810-1910)
}

Circe Maria Fernandes Bittencourt

Universidade de São Paulo

\begin{abstract}
This article presents considerations about the issue of the authorship of schoolbooks. The role of the authors of a schoolbook has been a controversial topic due to its ambiguity with respect to their rights and legal accountability. A schoolbook can offer substantial financial return to editors and authors, and such situation implies more complex and tense connections. Under this perspective, the article seeks to draw a profile of the first authors of Brazilian schoolbooks, from 1810 to 1910, with the purpose of characterizing the process through which different agents intervened in such production. The particular features of the production of a schoolbook as a text subjected to curricula, dependent on the approval of official educational bodies, and the commercialization and circulation conditions are indicated to show who were the authors that accepted those impositions. The article also presents the demands placed on the elaboration of schoolbooks by the changes in the books' target public. Initially prepared for teachers, the schoolbook gradually becomes a book for the pupil. Along this process, the pedagogical framework and the target public begin to demand greater care with language and with the constitution of new "didactic genres" directed at the elementary level. The profile of the author of a schoolbook changes, as does his/her autonomy, accentuating the relations between editor and author.
\end{abstract}

\section{Keywords}

Schoolbook - Authorship - Publishers - Author-function.

\section{Contact:}

Circe Maria F. Bittencourt

R. Maria Tereza F. Rodrigues, 219

05327-000 - São Paulo - SP

e-mail: circe@usp.br 


\section{Autores de compêndios e livros de leitura}

A história do livro didático inclui em suas abordagens a figura do autor, e este é o tema deste artigo, o qual, por sua vez, poderia ter como título "Quem foram os primeiros autores de livros didáticos no Brasil?".

Diferentemente de outras obras impressas, o livro didático possui peculiaridades em sua produção, circulação e uso, entre elas a da autoria, por meio da qual é possível ver a distinção entre o trabalho de escrever um texto e o de fabricar um livro.

A identificação da autoria dos livros didáticos tornou-se mais complexa na medida em que o ato de escrever o texto e o de transformálo em livro passaram por intensas transformações, as quais geraram polêmicas que se intensificaram nos últimos anos. Uma rápida leitura da ficha técnica, por exemplo, apresentada na contracapa das obras didáticas produzidas a partir da década de 1990, comprova que o papel do autor de uma obra didática tem se modificado em decorrência das inovações tecnológicas impostas pela fabricação do livro. Copidesque, revisor de texto, pesquisador iconográfico, entre outros, constituem uma equipe cada vez mais numerosa de pessoas responsáveis pelo livro, e o autor do texto, embora permaneça encabeçando esse conjunto de profissionais, nem sempre é a figura principal.

A autoria do livro didático tem passado por transformações ligadas às especificidades desse produto cultural, notadamente o retorno financeiro considerável que ele traz, sobretudo no caso de países como o Brasil, com um expressivo público escolar e um mercado assegurado pelo Estado na compra e distribuição de livros para as escolas públicas. Nos últimos anos, o interesse de editoras estrangeiras, que tem se concretizado na compra ou associações com empresas nacionais, conduz a transformações que afetam o papel do autor do livro escolar. Para agilizar a produção e criar padrões uniformes para o livro didático dilui-se a figura do autor por intermédio da compra de textos de vários escritores, textos que se integram em um processo de adaptações nas mãos de técnicos especializados. Desse modo, não se pode mais identificar quem efetivamente escreveu o texto. A nova situação demonstra que o livro didático é uma mercadoria que gera lucros consideráveis para as editoras, mas que coloca a pergunta inevitável sobre a função do autor, entendido como escritor do texto, e seus direitos de propriedade em relação à obra produzida.

A constatação de alguns dos problemas que envolvem os autores quanto ao seu papel na elaboração do livro nos faz indagar se tensões e conflitos dessa natureza são inerentes à produção do livro didático e, portanto, visíveis em outros momentos de sua história. Dessa forma, a preocupação em traçar o perfil dos primeiros autores de livros didáticos, no decorrer do século XIX e início do século XX, centrou-se na apreensão das articulações entre os diferentes sujeitos sempre presentes na produção didática, destacando a atuação do Estado e das editoras.

\section{Os autores na história do livro didático}

Pesquisadores voltados para a história da alfabetização ou das disciplinas escolares sempre demonstraram interesse por determinados autores cujos livros foram amplamente utilizados em sua época. Um dos trabalhos pioneiros sobre o tema foi o de Marisa Lajolo (1982), no qual se resgatam questões educacionais de um período que havia sido estudado mais pelos textos legislativos, pelos discursos oficiais, do que pela produção realizada para a escola e suas práticas efetivas de ensino, estudo que praticamente não havia sido feito até então.

Outros autores de obras didáticas que foram referências para várias gerações de estudantes tornaram-se objeto de estudos a partir dos anos 1990, sendo abordados com enfoques diversos. Conceição Cabrini (1994) percorreu o itinerário da produção de Felisberto de Carvalho (1886), autor do final do século XIX cuja obra era ainda utilizada em meados do século 
$X X$, com forte presença na memória de várias gerações nas mais variadas regiões do país. Selma Rinaldi de Mattos analisou os manuais de História do Brasil de Joaquim Manuel de Macedo, e várias pesquisas mostram o papel dos professores do Colégio Pedro 11 na produção de obras didáticas das variadas disciplinas.

Entre os franceses, a preferência da pesquisa de autores didáticos tem sido igualmente sobre os que ficaram na memória de gerações de estudantes. Os autores de livros de história encabeçaram as preferências. Ernest Lavisse $^{1}$ e os textos que escreveu para a escola primária francesa, após o advento da Terceira República, foi um deles.

Um livro e não exatamente seu autor, Le tour de la France par deux enfants, tem sido alvo de atenção, pela enorme repercussão que teve no período que antecedeu à Guerra de 1914-1918, tornando-se importante fonte para se determinar o alcance de um livro escolar na formação ideológica dos jovens. 0 livro representa o inconformismo dos grupos republicanos franceses, perdedores da guerra contra os alemães e que prepararam uma revanche, expressa na Primeira Grande Guerra. ${ }^{2}$ Uma obra que tem chamado a atenção de pesquisadores pela sua longa vida nas salas de aula na Itália e pelas traduções e adaptações em diversos outros países é Cuore (Coração), do italiano De Amicis, publicado pela primeira vez em $1886 .^{3}$

Nesses casos, os autores são na maioria dos casos vistos pelo seu papel de escritor de obras marcantes, personalizadas e representativas na formação de determinadas gerações de alunos. 0 objetivo central é analisar o conteúdo da obra, sua importância como veículo de ideologia, valores, métodos de ensino e, majoritariamente, no caso dos autores de obras didáticas do ensino secundário, é destacar seu papel na constituição das disciplinas escolares.

Mas se deslocamos o foco da pesquisa do conteúdo de determinadas obras e seu autor para um conjunto de autores e seu papel na produção da obra didática, surgem novas exigências sobre conceitos e categorias de análise. Uma contribuição importante têm sido as reflexões de Roger Chartier (1997), em seus estudos sobre a história do livro e sobre a cultura letrada. Diferentemente dos pesquisadores de livros didáticos, estudar os autores não foi muito usual na história do livro. A nítida distinção entre o trabalho de escrever um texto e o de fabricar um livro foi alvo de estudos que se voltaram sobre a materialidade dos livros, especialmente entre os historiadores do mundo de língua inglesa. Entre os franceses as pesquisas se voltaram mais sobre a circulação do livro, a posse desigual pelos diferentes grupos sociais e a diversidade das práticas de leitura. 0 foco era o conteúdo do texto e seus signos, mas excluía-se o autor.

Para os recentes trabalhos sobre o autor do livro, Chartier (1997) recupera a contribuição de Foucault no ensaio "Qu'est-ce un auteur?”. Foucault coloca o autor como personagem importante ao fornecer um nome próprio às obras e acentua o caráter de responsabilidade que presume um estado de direito e, portanto, sujeito a sanções penais como proprietário de uma obra literária. Destaca, nessa perspectiva, a função-autor que necessariamente estabelece vínculos diversos com a obra e cria identidades. A produção de textos realizase sob tais condições e cria status diversos entre autores, dependendo da variação dos textos: os discursos "científicos" e os discursos "literários". Chartier adverte, baseando-se na preocupação de Foucault sobre direitos e discriminações em relação ao autor do texto, quanto ao cuidado em identificar a produção de diferentes discursos em momentos históricos específicos. 0 valor comercial da obra, a constituição de direitos autorais, conflitos entre

1. Sobre Ernest Lavisse ver Nora (1984).

2. Sobre o livro Le tour de la France par deux enfants de G. Bruno, publicado em 1877, destacam-se o de Ouzouf, J. et M. Le tour de la France par deux enfants: le petit livre rouge de la Republique; 0 de Nora (1984), o de Dupuy (1953) e de Siepe (1988). No Brasil, Olavo Bilac e Manuel Bomfim escreveram o famoso livro de leitura Através do Brasil inspirados nessa obra francesa.

3. Entre outras publicações sobre esta obra destaca-se a de Catarsi (1896). A tradução em português publicada em 1891, pela editora de Francisco Alves, foi feita por João Ribeiro. 
autor e editor, sanções jurídicas sobre os autores analisados por Chartier em produções nos séculos XVIl e XVIIl, indicam a necessidade de novos enfoques e a complexidade na abordagem do tema.

Tendo por base essa dimensão da função-autor, a pesquisa sobre os autores de obras didáticas exige uma ampliação de perspectiva alterando os limites do contexto biográfico em suas relações com o conteúdo expresso no texto. Os conflitos, tensões, acordos, discriminações, satisfações, fazem parte da história dos autores dos livros e há necessidade de inclusão de outras fontes documentais. Requer uma leitura bastante atenta de catálogos das editoras, de contratos ou correspondência entre editores e autores e, cabe assinalar, que há dificuldades em ter acesso a essas fontes por causa das empresas editoriais, que nem sempre permitem a consulta de seus arquivos, além do fato de serem escassas. Ademais, nos livros didáticos existem outras informações além do seu conteúdo didático, que se encontram nos prefácios, prólogos, advertências, introduções. Nestes, é possivel entrever mensagens dos autores e os possíveis diálogos com os professores, com as autoridades e com os alunos e suas famílias.

0 estudo dos primeiros autores de livros didáticos brasileiros é uma tentativa de indicar essas relações complexas, situá-los junto aos demais sujeitos que constituíram a história da educação escolar no século XIX e início do século XX.

\section{Surgem os autores de livros didáticos brasileiros}

0 autor de uma obra didática deve ser, em princípio, um seguidor dos programas oficiais propostos pela política educacional. Mas, além da vinculação aos ditames oficiais, o autor é dependente do editor, do fabricante do seu texto, dependência que ocorre em vários momentos, iniciando pela aceitação da obra para publicação e em todo o processo de transformação do seu manuscrito em objeto de leitura, um material didático a ser posto no mercado.
A história do livro didático brasileiro tem demonstrado que existem preconceitos em relação aos intelectuais que se dedicam à produção didática, considerando-se o livro escolar como uma obra "menor", um trabalho secundário no currículo acadêmico. No século XIX e início do século $X X$, período inicial dessa produção, a situação não era muito diferente embora houvesse algumas particularidades. ldentificar o grupo de intelectuais que se sujeitaram às imposições do poder educacional e das editoras merece, assim, considerações significativas para aprofundar o conhecimento sobre o livro didático e o papel que tem desempenhado na produção da cultura escolar.

Algumas indagações são inevitáveis: Estariam nossos primeiros autores motivados pelas vantagens financeiras que a empreitada poderia oferecer ou seriam outros os motivos que os levaram à realização de um trabalho intelectual considerado inferior na hierarquia da produção do conhecimento?

Um ponto inicial para um estudo dessa natureza é conhecer suas produções, buscando entender a concepção que possuíam sobre 0 papel do livro didático na educação escolar. Os livros escolares foram considerados, pelos autores, como instrumento de trabalho do professor ou seu substituto? Qual seria a concepção de uso do livro didático em uma época onde praticamente inexistiam instituições de formação de professores, tanto para o ensino das primeiras letras quanto para o nível secundário?

$\mathrm{Na}$ listagem de autores de obras didáticas deparamos com alguns nomes famosos da literatura, da vida política e cultural do século XIX e início do século atual. Muitos desses literatos e políticos tiveram suas obras e ações analisadas, decifradas sob várias abordagens, mas foram praticamente ignorados enquanto autores de obras destinadas às escolas. Marisa Lajolo assinala que "o livro escolar, quando observado no conjunto da obra de um autor como Bilac, é quase sempre visto como obra menor" (1982, p. 20). Da mesma forma, é significativo o trabalho sobre o cônego Fernandes 
Pinheiro, escrito por um seu descendente, ao procurar marcar apenas sua obra de historiador e mais especificamente seu pioneirismo na história da literatura no Brasil. A extensa produção didática do cônego é lembrada em poucas linhas, em um único parágrafo (Pinheiro, 1978).

Quem foram, então, os pioneiros da produção didática brasileira?

Considerando o período entre 1810 e 1910, pode-se verificar uma mudança do perfil dos autores. Um primeiro grupo iniciou sua produção a partir da chegada da família real portuguesa no Brasil, e suas obras foram produzidas pela Impressão Régia, mas podemos identificar uma primeira "geração" a partir de 1827, autores preocupados com a organização dos cursos secundários e superiores, apenas esboçando algumas contribuições para o ensino de "primeiras letras". Uma segunda "geração" começou a se delinear em torno dos anos 1880, quando as transformações da política liberal e o tema do nacionalismo se impuseram, gerando discussões sobre a necessidade da disseminação do saber escolar para outros setores da sociedade, ampliando e reformulando o conceito de "cidadão brasileiro", criando-se uma literatura que, sem abandonar o secundário, dedicaram-se à constituição do saber da escola elementar.

\section{“Sábios", políticos e professores em ação}

Senador do Império do Brasil; Conselheiro de Estado; Grão-Cruz da Imperial Ordem do Cruzeiro; Cavaleiro da de Cristo; Brigadeiro do Imperial Corpo de Engenheiros; Bacharel Formado em Matemática pela Universidade de Coimbra; Lente jubilado da academia Real da Marinha de Lisboa; Membro honorário da Sociedade Literária do Rio de Janeiro, e do Instituto Histórico e Geográfico Brasileiro; Sócio da Academia Real das Ciências de Lisboa, da Sociedade Geográfica de Paris; da Academia da Industria Francesa; Membro Honorário da Sociedade Etnológica de Paris; Sócio da Academia dos
Liceus, e da Arcádia de Roma; membro correspondente do Instituto Nacional de Washington; etc.

(Folha de rosto de Elementos de geometria, do marquês de Paranaguá)

Esta apresentação do autor, do marquês de Paranaguá, inscrita na página de rosto de sua obra escolar de 1846, nos sugeriu uma possível classificação dos autores, dentre os inúmeros nomes elencados nos catálogos das editoras. As referências sobre a participação do marquês nos meios culturais eruditos da época estabelecem prontamente a vinculação entre o grupo de intelectuais próximos ao poder do Estado e os primeiros autores das obras destinadas à divulgação do saber para instituições escolares. 0 perfil dos autores dessa "primeira geração" é o de homens pertencentes à elite intelectual e política da recente nação, conforme está visível na "biografia" do autor citado.

As referências do marquês de Paranaguá apresentadas indicam, além da sua formação acadêmica e de seus contatos com os grandes centros internacionais do mundo científico, que ele era uma figura de destaque nos meios políticos: senador do Império e conselheiro do Estado.

E ele não foi um exemplo isolado. Outros personagens do cenário político também se aventuraram na tarefa de redigir obras a serem divulgadas nas escolas de formação das futuras elites. José Justiniano da Rocha (1866), também senador do Império, e o visconde de Cairu (Lisboa, 1827), figura importante do governo de d. Pedro 1, deram suas contribuições nesse sentido.

A leitura das obras desses autores mostra que o interesse maior deles residia na questão da formação moral e que eles estavam atentos aos textos que eram oferecidos aos jovens leitores. Na Introdução do livro escolar do visconde de Cairu, o autor expressou seu temor pela disseminação da palavra escrita para "jovens incautos”. Temia também que as classes trabalhadoras pudessem se instruir e aspirassem a mudanças de sua condição e seriam "seduzi- 
dos para Revoluções por insidiosos demagogos" (Lisboa, 1827, p. 21).

José Justiniano da Rocha em 1866, ao adaptar o célebre poema Os lusíadas, de Camões, para os alunos, intitulou seu livro de Camoniana Brasileira e nele resumiu os trechos mais belos do poema dentro de cuidadosos critérios. 0 crivo da censura fez com que a maioria das estrofes do Canto IX, do episódio da llha dos Amores, fosse cortada. As leituras de cenas amorosas eram, assim, vetadas aos jovens adolescentes.

0 marquês de Paranaguá era também "membro honorário do Instituto Histórico e Geográfico Brasileiro”, uma vinculação significativa a uma instituição "científica e cultural" simbólica do Império e das primeiras décadas da República.

Da lista dos iniciadores do Instituto Histórico e Geográfico Brasileiro fazia parte um grupo classificado por Lilia Moritz Schwarcz "como a nata da política imperial, boa parte dela nascida em Portugal e fiéis servidores da Casa de Bragança” (1989, p. 21). A presença do poder político no IHGB foi constante durante todo o império, tendo d. Pedro 11 participado assiduamente de suas reuniões. Não é, também, por mero acaso que encontramos na lista do IHGB vários nomes de professores do Colégio Pedro 11 e muitos deles foram os responsáveis pelas mais conhecidas e divulgadas obras didáticas destinadas ao curso secundário.

Tais autores possuíam, portanto, estreitas ligações com o poder institucional responsável pela política educacional do Estado, não apenas porque eram obrigados a seguir os programas estabelecidos, mas porque estavam "no lugar" onde este mesmo saber era produzido. A primeira interlocução que os autores estabeleciam era exatamente com o poder educacional institucionalmente organizado. 0 "lugar" de sua produção situava-se junto ao poder e realizavase para consolidar o poder instituído por intermédio dos colégios destinados à formação das elites, dialogando com intelectuais e políticos responsáveis pela política educacional. 0 mesmo ocorreu com alguns dos autores das províncias que estavam ligados a institutos congêneres.

Muitas figuras que se destacaram como secretários do lHGB foram também autores de livros didáticos. 0 cônego Caetano Fernandes Pinheiro (1859-1876), dr. Duarte Moreira de Azevedo (1880-1886), Joaquim Manuel de Macedo (1852-1856) e Max Fleiuss (19001905). Além do papel que desempenharam na entidade, como secretários, tinham todos eles uma atuação dinâmica, conciliando seu trabalho de "cientistas" com outros cargos, quer como professores, quer como profissionais liberais. Os secretários compuseram um segundo escalão importante para a sobrevivência da instituição e deles dependia a imagem e a produção científica do lHGB. Sem serem nomes famosos, eram os que lutavam para conseguir aproximar-se e desfrutar dos privilégios do poder. 0 lHGB abrigou outros nomes, entre seus sócios efetivos, que deixaram textos escolares como uma de suas contribuições culturais sem que, entretanto, alardeassem estas atividades. Em suas bibliografias é difícil encontrar as obras didáticas que produziram.

Outra instituição significativa que abrigou autores de livros foi a Escola Militar instalada no Rio de Janeiro, em 1810. A partir do momento em que foi criada, essa instituição teve que se haver com a questão dos compêndios a serem adotados. Essa escola, responsável pelo ensino das ciências matemáticas, físicas, química, história natural, técnicas de guerra e fortificações, cuidou da oferta de textos escolares, embora com produção reduzida nas primeiras décadas, no que se refere a trabalhos didáticos próprios. Os lentes limitaram-se a realizar traduções, ou adaptações de textos estrangeiros ou, preferencialmente, recorriam às obras de Portugal. Entretanto, iniciando a década de 1840, durante as disputas políticas e sociais da fase regencial, com a questão da unidade nacional e a nova configuração do papel político dos militares, houve a necessidade de uma produção de obras didáticas locais, que deveriam se encarregar, entre ou- 
tros aspectos, de esboçar os contornos territoriais da nação independente. A Escola Militar foi, então, o lugar institucional responsável pelo aparecimento dos primeiros compêndios dedicados ao ensino das disciplinas formadoras da "nacionalidade", especialmente história e geografia.

As relações entre os autores e editores correspondem ao percurso histórico da constituição das editoras no Brasil. Após o término do monopólio da Impressão Régia em 1822, teve início a transferência dos encargos editoriais para o setor privado. A Tipografia Nacional continuou publicando obras didáticas em número restrito e editores de origem estrangeira passaram a se ocupar da produção nacional, mas sempre vinculados aos países europeus principalmente. As marcas editoriais francesas, em especial, foram se consolidando em razão de nossa dependência das técnicas de produção e das políticas de importação. ${ }^{4}$

Até 1885 três editoras se destacaram na produção de obras didáticas. A editora dos irmãos Laemmert

surgiu da iniciativa de Eduard Laemmert, nascido em Baden e chegou ao Brasil como sócio da firma do livreiro francês Bossange. Em 1838 resolveu criar sua própria firma e associou-se ao seu irmão Heinrich. (...) A. E. \&t H. Laemmert foi praticamente a substituta da Tipografia Nacional, nova denominação da Impressão Régia. (Bittencourt, 1993, p. 82)

A editora de B. L. Garnier que, segundo Hallewell, foi o "primeiro editor a fazer um esforço real para atender às necessidades de livros escolares brasileiros, correndo um risco comercial por sua própria iniciativa" (1985, p. 144). E a terceira editora que se destacou nesse período foi a firma de Nicolau Alves, livreiro português que a partir dos anos 1880 teve como sócio o sobrinho Francisco Alves, figura significativa na mudança da editora, transformando-a na mais importante empresa de obras didáticas entre 1880 e 1920.
As estratégias das primeiras editoras centraram-se na aproximação ao poder institucional, podendo-se entender por essa via o critério de escolha dos autores. Estes correspondiam a um perfil que expressava essa dependência política. Compêndios, cartilhas eram textos que precisavam da aprovação institucional para que pudessem circular nas escolas, o que acabava por direcionar as opções dos editores na seleção dos autores. Entende-se, portanto, a preferência por autores oriundos do Colégio Pedro 11 ou da Academia Militar. Além de assegurarem uma vendagem, dificilmente seus nomes seriam vetados pelos conselhos educacionais que avaliavam as obras, inclusive porque vários membros do lHGB compunham as comissões de avaliação das obras didáticas. A figura do autor era assim realçada, sua biografia geralmente exposta na página de rosto, e os editores esmeravam-se em valorizar sua posição social.

A concepção de livro didático e a sua destinação eram determinações quase exclusivas do poder político educacional, que procurava, no grupo da elite intelectual, apoio para a produção desse tipo de literatura. Tivemos assim, na geração dos iniciadores da produção didática, figuras próximas ao governo, escritores de obras literárias, sobretudo os principais encarregados do "fazer científico" da época. Os compêndios que escreveram para o público estudantil eram de literatura, gramática, história e geografia, dedicados ao ensino secundário, majoritariamente, e em menor escala para as "escolas de primeiras letras". Os autores, com raras exceções e pela condição da disciplina, inspiravam-se ou mesmo adaptavam obras estrangeiras. Os livros de matemática, então desdobrada em aritmética, geometria, álgebra exemplificam essa produção modelada em obras européias, lembrando ainda que os programas curriculares eram originários e "traduzidos”, em sua maioria, da França.

4. Um dos problemas das editoras e gráficas era o da impressão, porque o preço do papel e das tintas variava muito, daí a opção de muitos editores pela impressão de obras na Europa. 


\section{Uma nova "geração" de autores entra em cena}

Um segundo grupo de escritores começou seu trabalho a partir do momento em que o ensino elementar das escolas públicas começou a se avultar. Os anos de 1870 e 1880 marcaram o início do crescimento escolar e o surgimento de escritores provenientes de outras esferas sociais. Pfromm Netto assinala que o movimento responsável pelo crescimento do ensino elementar possibilitou

as condições favoráveis que estimularam, em educadores brasileiros, o desejo de elaborar livros de leitura e de outros textos didáticos para uso dos alunos e professores do ensino elementar. 0 baiano Abílio Cesar Borges, primeiramente, e mais tarde, Felisberto de Carvalho, Hilário Ribeiro, Romão Puiggari, Arnaldo de Oliveira Barreto, Francisco Vianna, João Köpke e outros produziram nossas primeiras séries graduadas de livros de leitura. Livros que foram verdadeiramente nacionais (...) concorrendo de modo nada desprezível para a unidade brasileira de sentimento. (Pfrom Netto, 1974, p. 170)

As biografias dos nomes citados indicam uma diferenciação de formação e experiências quando comparamos com o grupo anterior, mais homogêneo em sua composição.

Os autores dessa geração possuíam, na maioria das vezes, experiências pedagógicas provenientes de cursos primários, secundários ou de escolas normais voltadas para a formação de professores. A prática pedagógica desses autores refletiu, parcialmente, uma preocupação menos limitada quanto às opções educacionais, saindo da esfera do ensino puramente destinado à formação das elites.

A qualidade de "sábio", capaz de adaptar os textos estrangeiros, realizando escrituras baseadas em obras científicas, seguindo o modelo de compêndios destinados às elites de outros países passou a ser alvo de críticas por parte de alguns desses educadores. Surgiram preocupações com a elaboração de livros destinados especialmente às crianças, atentando para as especificidades do público infantil.

As editoras, por seu turno, considerando seu público consumidor, estavam atentas às preferências dos professores. Livros do nível secundário com maior sucesso de venda eram os provenientes "das aulas" dos professores. 0 livro Lições de História do Brasil, de Joaquim Manuel de Macedo, se originou das aulas desse professor no Colégio Pedro 11 e inovava pelos exercícios e atividades pedagógicas ao final de cada capítulo ou "lição". ${ }^{5}$ Para professores sem formação específica, o livro didático representava "o método de ensino", além de conter o conteúdo específico da disciplina. A formação do professor, ao ser constituída na prática, no “aprender fazendo" exigia uma produção didática específica que intelectuais preocupados com o conhecimento científico ou literário, mas sem a vivência da sala de aula, eram incapazes de produzir com sucesso.

Esse período correspondeu a uma sensível mudança quanto ao público do livro didático. 0 livro didático traz, desde sua origem, uma ambigüidade no que se refere ao seu público. 0 professor é figura central, mas existe o aluno. 0 livro didático não pode separá-los. A partir da segunda metade do século XIX passou a se tornar mais claro que o livro didático não era um material de uso exclusivo do professor, que transcrevia ou ditava partes do livro nas aulas, mas que ele precisava ir diretamente para as mãos dos alunos. 0 aluno era (e ainda é) um público compulsório, mas assumilo como consumidor direto do livro significava, para autores e editores, atender a novas exigências, transformando e aperfeiçoando a linguagem do livro. As ilustrações começaram a se tornar uma necessidade, assim como surgiram novos "gêneros didáticos", destacando os livros

5. Essa característica inovadora explica as inúmeras edições desse livro, cuja primeira edição é de 1861 e a última, de 1924. 
de leitura e os livros de lições de coisas, não se limitando mais a compêndios e cartilhas.

Escrever um livro didático apresentava desafios, e os editores possuíam consciência da complexidade da tarefa. Entre outros desafios havia o de elaborar textos que pudessem mesclar narrativas e "atividades" de aprendizagem, compondo as relações de ensino e aprendizagem. 0 "discurso" do livro didático é sempre complexo e de difícil denominação, variando entre um "discurso científico" e um "discurso literário”.

A valorização das experiências pedagógicas do escritor passou a ser fortemente considerada por parte dos editores como critério de escolha dos autores. Da mesma forma, a seleção destes voltava-se para os que acompanhavam os avanços pedagógicos dos países onde a alfabetização se estendia para uma população cada vez maior. A qualidade principal, entretanto, exigida do autor de livro didático para a escola elementar, era sua capacidade de "bom escritor", ou seja, possuir qualidades literárias para atingir a especificidade de um público infantil e juvenil.

A idealização governamental dos autores das obras didáticas, nos primórdios do século XIX, centrada na figura do "sábio" para cumprir esta tarefa "patriótica" modificou-se, mas sem desaparecer totalmente. 0 discurso sobre a elaboração de textos escolares como “missão patriótica” permaneceu. As modificações ocorreram sob a concepção de "sábio" ou do "sábio mais adequado" para escrever compêndios e livros de leitura. 0 incentivo governamental marcante da época foi o de oferecer concursos para "melhores obras" que teriam a publicação garantida e prêmios monetários aos autores. 0 "lugar" da produção deslocou-se, situando-se na esfera mais específica do poder educacional, e provocou novas articulações dos setores editoriais na escolha dos autores.

A nova "geração" de autores caracterizou-se por sua heterogeneidade, por divergências inevitáveis, uma vez que produziam para um público ampliado, não se limitando mais aos filhos dos grandes proprietários rurais e comerciantes. Tratava-se de um público bastante diferenciado, compreendido por alunos de escolas de ensino elementar, com idades variáveis, por adolescentes desejosos de seguir carreiras no setor terciário, muitas vezes oriundos de classes menos favorecidas da sociedade e por jovens da elite econômica, agora acrescida por elementos do sexo feminino.

\section{Autores autônomos}

Um ponto de divergência entre os autores relacionava-se ao tema da alfabetização. A opção do método de alfabetização não se explicava apenas por razões didáticas. Ela expressou conflitos políticos que começaram nos últimos anos da década de 1870 e se estenderam até o início do século $X X$.

A escolha do método analítico para a alfabetização, em oposição ao usual método sintético, representava a posição dos grupos de educadores defensores de uma escola laica. Os seguidores do método analítico eram, em sua maioria, republicanos com o discurso voltado para uma democratização do saber escolar e, contrários ao espírito tradicional de educação, cujo ensino era calcado em métodos da lgreja.

A divulgação de autores e suas obras pelo jornal a Província de São Paulo é uma amostra da luta pela implantação de uma escola laica. 0 jornal paulista propugnava um liberalismo no qual a escola particular era o símbolo de "liberdade de ensino", entendida como escola livre das imposições da Igreja Católica e do Estado. O jornal Província de São Paulo foi um veículo importante para fazer propaganda de autores oriundos de escolas particulares leigas, esforçando-se em criar uma imagem para a escola privada como sendo a de melhor qualidade. Os proprietários do periódico paulista entendiam que a divulgação das obras escolares, notadamente de diretores de escolas particulares, significava prestigiar e moldar a opinião pública para as vantagens da iniciativa particular, embora não abdicassem da defesa das subvenções de verbas do Estado para tais iniciativas. 
O grupo de autores divulgados pelo jornal a Província de São Paulo foram defensores de um ensino renovado, moldado, muitas vezes nos modelos norte-americanos. Foram os precursores da formulação de um discurso sobre a neutralidade do ensino, objetivo e sem dogmas. Na divulgação de livros escolares, seus autores prediletos foram Abílio César Borges, João Köpke, ambos proprietários de escolas particulares.

0 hábito de diretores de escolas particulares se dedicarem à composição de livros escolares não era recente. Antonio Álvaro Pereira Coruja, considerado como autor da primeira gramática escolar brasileira, publicada em 1835, no Rio Grande do Sul “organizou [,] e manteve na Corte, um colégio famoso, o $\mathrm{Co}$ légio Minerva, onde continuou a publicar livros escolares de variadas disciplinas" (Pfhrom Netto, 1974, p. 194).

Menezes de Vieira, antes de tornar-se diretor do Pedagogium, era conhecido na capital do Império pelo seu colégio, famoso por ter introduzido o método Fröebel no Brasil, incentivando a criação dos "Jardins de Infância". Menezes Vieira aliava a direção escolar com a produção de obras didáticas para o ensino primário, que ele próprio se encarregava de publicar, tendo inclusive criado a Tipografia do Colégio Menezes Vieira. Os livros didáticos eram anunciados em revistas e jornais do Rio de Janeiro, difundindo com a mesma ênfase do jornal A Província de São Paulo, o ideário da escola privada:

As noções de gramática que o consciencioso e adiantado diretor do Colégio Menezes Vieira acaba de dar a estampa representam um trabalho que se funda na racionalidade do ensino intuitivo, e conseqüentemente da educação positiva, a única que pode formar cidadãos suculentamente instruídos e aptos para os misteres da vida e da sociedade. Ali se encontram os processos recomendados pela moderna ciência pedagógica: a instrução, o raciocínio e a prática aliaram-se nas páginas do precioso livrinho. (Vieira, 1887)
João Köpke foi outro exemplo de autor que desenvolveu suas habilidades de escritor de obras escolares em seu próprio estabelecimento de ensino, a escola Neutralidade, em São Paulo. Köpke iniciou sua carreira de escritor e diretor na capital paulista, ficando conhecido como defensor do método analítico. A utilização do método analítico na alfabetização inseriu-se nas disputas e divergências políticas entre os próprios republicanos. Köpke criticava o método analítico de João de Deus, intelectual português e militante político cuja obra foi amplamente divulgada pelos republicanos mais radicais brasileiros. Silva Jardim foi um deles. Köpke reelaborou e adaptou o denominado método analítico, divulgando-o em vários livros escolares e suas divergências com Silva Jardim foram ocasionadas pela "ortodoxia positivista que separou de mim o estremo companheiro" (Köpke, 1896, p. 2).

Outros diretores poderiam ser citados, mas o autor que melhor pode representar esse grupo é Abílio César Borges. 0 "amigo das crianças” escreveu uma vastíssima obra didática, criou inúmeras escolas na Bahia, no Rio de Janeiro e em Barbacena, Minas Gerais. Muito elogiado, sendo agraciado com o nobre título de "barão de Macaúbas" pelo imperador, em razão dos "serviços prestados à grande causa patriótica: a educação”, teve biografias que destacaram suas obras escolares. Abílio César Borges, diretor geral da instrução da Bahia, fundou o Ginásio Baiano, e depois se transferiu para a Corte, no Rio de Janeiro, criou o Colégio Abílio e outro em Barbacena, Minas Gerais, atraindo os filhos das elites pelas inovações pedagógicas. 0 colégio da capital do país ficou reno-mado por combater a palmatória, criando uma imagem de escola laica moderna, em oposição ao modelo fradesco e truculento das escolas confessionais.

Entretanto, o método, o personagem e a obra didática foram objeto de críticas. Raul Pompéia, ex-aluno do famoso colégio, em sua obra $O$ Ateneu, revela outras facetas do diretor e sua obra: 
Eram boletins de propaganda pelas províncias, conferências em diversos pontos da cidade, a pedidos, à sustância, atochando a imprensa dos lugarejos, caixões, sobretudo, de livros elementares, fabricados às pressas com o ofegante e esbaforido concurso de professores prudentemente anônimos, caixões e mais caixões de volumes cartonados em Leipzig, inundando as escolas públicas de toda a parte com a sua invasão de capas azuis, róseas, amarelas em que o nome de Aristarco, inteiro e sonoro, oferecia-se ao pasmo venerador dos esfaimados de alfabeto dos confins da pátria. Os lugares que os não procuravam eram um belo dia surpreendido pela enchente gratuita, espontânea, irresistivel! E não havia senão aceitar a farinha daquela marca para o pão do espírito. (Pompéia, 1905, p. 8)

É difícil provar se o diretor Abílio contou com o concurso de "anônimos professores" como afirmou o autor do Ateneu, mas a quantidade e a variedade de obras que deixou podem lançar algumas dúvidas sobre a possibilidade de serem realmente trabalhos de um único indivíduo. Foram produzidas e postas em circulação, sob sua autoria, cerca de 400 mil volumes e 22 títulos, com variadas edições revisadas.

A existência de professores anônimos na composição de obras didáticas é difícil de ser detectada, mas desde meados do século XIX passou a existir a prática de autores renomados assinarem obras feitas por auxiliares desconhecidos, tornando-se uma espécie de marca registrada e, em situação oposta, existiram (ou existem) autores com pseudônimos, escondendo sua identidade. ${ }^{6}$

Mas independentemente das formas encontradas para a produção de textos didáticos, temos que o barão de Macaúbas assim como Joaquim José Menezes Vieira foram representantes de um grupo de autores específicos e significativos do processo de escolarização brasileira. Esmeraram-se em criar uma imagem de inovadores pedagógicos, com projetos centrados na escola particular mas sob a proteção do governo, monárquico ou republicano, que garantia o sucesso de suas escolas e de suas obras. Obras prestigiadas pela imprensa tiveram ainda uma peculiaridade: marcaram o movimento de laicização escolar. Em geral as obras desses autores sofreram várias reedições, mas não foram de "longa duração", limitando-se à primeira década do século $X X$.

Esses autores caracterizaram-se ainda por uma produção independente da escolha das editoras. Eram seus supostos autores de textos, encarregavam-se dos custos de edição e impressão e escolhiam as editoras para suas obras. Abílio César Borges teve um número considerável de livros publicados pela editora Aillaud, Guillard sediada em Paris. Aparentemente não tinha interesse lucrativo com a venda dos livros pelas informações que temos sobre a distribuição gratuita que fazia de suas obras por várias regiões do país. Entretanto, a proximidade com o poder imperial garantiu a aquisição de obras pelo governo para que o autor pudesse distribuir "gratuitamente" nas escolas. Juntamente com esses autores ligados às escolas particulares, a produção didática de setores religiosos também desempenhou um papel significativo nesse periodo.

Compondo a lista de professores que se tornaram famosos como escritores de compêndios, temos os oriundos de escolas protestantes de São Paulo: Antonio Trajano e Júlio Ribeiro. Esses autores foram bem aceitos por parte dos liberais paulistas, por representarem uma forma de oposição aos textos de autores católicos.

Antonio Trajano produziu livros de aritmética e álgebra para as escolas primárias e

6. 0 caso exemplar de autor "de marca registrada" foi Victor Duruy, historiador francês, ministro da Instrução Pública da França (1863 a 1869) e professor de história do Liceu Napoleão (antigo Liceu Saint Louis), um dos primeiros grandes nomes de autores didáticos da editora Hachette de $\mathrm{Pa}$ ris. Para a segunda situação temos o cônego Fernandes Pinheiro, que assinava obras como Sá e Menezes ou então escrevia textos sem que constasse a autoria: " 0 cônego dr. Joaquim Caetano Fernandes Pinheiro cede a B.L. Garnier a sua História Contemporânea desde 1815 até 1865, publicada sem o nome do autor mediante as seguintes condições (...)". Manuscrito Arquivo da Editora Itatiaia, Belo Horizonte. 
secundárias e com Aritmética elementar ilustrada, obra premiada na Exposição de 1883 do Rio de Janeiro, tornou-se um autor nacionalmente conhecido. Júlio Ribeiro, mais conhecido como romancista, foi "o verdadeiro introdutor, nas escolas, da nova e brilhante fase do ensino da língua portuguesa" (Almeida, 1889, p. 159).

A projeção de autores de origem protestante não significou a ausência de religiosos católicos na tarefa a que vinham se dedicando há tantos anos. Os jesuítas retomaram suas atividades pedagógicas lentamente no decorrer do século XIX e deixaram algumas obras escolares. 0 mais famoso escritor didático, dentre os jesuitas, foi o padre Rafael Maria Galanti, professor no Colégio Anchieta em Nova Friburgo. Os clérigos seculares que assumiram cátedras no Colégio Pedro 11 ocuparam-se da literatura escolar compondo livros próprios, como o cônego Fernandes Pinheiro, ou como tradutores. Personalidades mais eminentes da hierarquia religiosa também contribuiram para os trabalhos pedagógicos, notadamente produzindo livros de religião, disciplina obrigatória durante o Império, e catecismos ou livros de História Sagrada.

A produção das obras de autores religiosos, em princípio, deveria seguir os programas curriculares oficiais, entretanto, sua circulação dependia da autorização eclesiástica. 0 Imprimatur, assinado e datado por autoridades religiosas dos locais da edição, visível na contracapa do livro, representava a censura e a forma de interferência no texto dos autores em relação à produção didática. A edição de qualquer livro destinado às escolas católicas dependia dessa chancela.

A contribuição maior do setor católico para a literatura escolar ocorreu com a vinda dos irmãos maristas e a instalação de sua editora, a FTD. As obras didáticas, de caráter marcadamente europeu, compuseram um acervo didático que se opôs à tendência "nacionalista” então em voga. Os autores anônimos da FTD começaram a disseminar livros impressos no exterior, traduções que em sua maioria foram sendo consumidas pelo número crescente de escolas confessionais católicas no início do século XX. A questão do "nacionalismo educacional" encontrou em tais autores verdadeiros opositores, incluindo as questões metodológicas e pedagógicas, com muitas obras mantenedoras do método catequético organizado com perguntas e respostas.

\section{Autores de best-sellers didáticos}

Durante o período republicano, sobretudo, pudemos listar um número significativo de autores que exerciam cargo de inspetores de instrução ou que fizeram parte de Conselhos de Instrução. Embora muitos deles tivessem produzido obras pouco conhecidas, limitadas a pouco mais de uma edição, alguns conseguiram se sobressair, tornando-se nomes famosos da literatura escolar.

0 mais famoso escritor de livros escolares que iniciou sua carreira como inspetor escolar foi Olavo Bilac. 0 renomado poeta começou a compor textos escolares com Manuel Bomfim, então diretor de Instrução Pública do Distrito Federal. Juntos escreveram o Livro de composição, um Livro de leitura e o célebre Através do Brasil, publicado anos mais tarde, em 1910. Com Coelho Netto, Bilac publicou Contos pátrios em 1904, obra de inúmeras edições assim como suas Poesias infantis.

Um outro autor de sucesso cuja origem foi a prática escolar foi o já citado Felisberto de Carvalho. Na página de rosto do Dicionário gramatical, ele era apresentado como

professor público da província do Rio de Janeiro, habilitado pela Escola Normal da mesma província; ex-professor interino da cadeira de português da extinta escola Normal para o sexo feminino, professor interino da segunda cadeira na atual escola; membro do Conselho de Instrução. (Carvalho, 1886)

Felisberto de Carvalho escreveu obras de gramática, geografia, educação moral e cívi- 
ca, história natural e higiene sendo, entretanto, seus livros mais famosos e de "longa duração", os cinco livros de leitura publicados inicialmente na década de 1880 com reedições até 1959.

Obras e autores que se tornaram famosos e alcançaram altos índices de vendagem representavam o espírito de renovação educacional iniciado no final do século XIX. As posições que muitos desses autores ocupavam em setores educacionais proporcionavam a elaboração de textos com maior probabilidade de aprovação por atenderem aos critérios dos Conselhos de Instrução Pública.

As relações entre editor e autor eram muito próximas quanto aos procedimentos para a obtenção de certidão de aprovação dos livros pelos Conselhos Diretores de Instrução Pública. Mas, além da aprovação oficial, as editoras escoIhiam autores "que tivessem uma margem de venda garantida”, com aceitação pelo público. 0 autor, por outro lado, esperava da editora "a infra-estrutura para a composição, propaganda e distribuição de seus livros” (Cabrini, 1994, p. 66). Um editor em particular percebeu o novo cenário educacional e as perspectivas mercadológicas que se abriam. Francisco Alves, depois de assumir a firma criada pelo tio Nicolau Alves a partir de 1897, passou a investir com maior empenho na produção didática e acabou quase que monopolizando a produção nessa área a partir do século XX. Além de estender uma eficiente rede para a venda dos livros por todo o país, Francisco Alves comprou várias editoras médias e pequenas. De acordo com Hallewell,

muitas dessas aquisições - houve pelo menos dez delas - foram feitas para conseguir determinados direitos de edição. Francisco Alves comprou a pequenina livraria da Viúva Azevedo, apenas para obter os direitos da Antologia nacional de Fausto Barreto e Carlos Laet, amplamente adotadas nas escolas. A Livraria Melilo, de São Paulo, foi comprada porque os livros de João Köpke por ela editados eram os principais competidores dos de Felisberto
Rodrigues Pereira de Carvalho, editados pela Alves. (1985, p. 211)

Francisco Alves, além das estratégias de venda e formas de atração de autores com obras já conhecidas, oferecia contratos que garantiam retorno financeiro significativo, mesmo para professores renomados de escolas famosas. 0 caso de João Ribeiro, professor do Colégio Pedro 11 e autor de vários livros de história e literatura para o ensino primário e secundário, expressa a opção do autor para seu ofício de "escritor de obras didáticas":

João Ribeiro (...) de família numerosa, sem grandes recursos. Necessitava dedicar-se ao ensino e à elaboração de livros didáticos, como forma de trabalho para o sustento dos seus. (...) Mas o argumento decisivo - financeiro - justificava a opção por compêndios, de retorno mais garantido, porque escritos por um Catedrático do Colégio, nessa época ainda rótulo reconhecido socialmente, por isto mesmo apresentado na capa das obras didáticas. (Gasparello, 2004, p. 163)

Os ganhos financeiros dos autores incentivaram de maneira considerável essa geração de escritores de obras didáticas, conforme atestam as biografias de muitos deles. Havia o interesse em difundir métodos de ensino renovados, havia interesses de interferência na formação das novas gerações, mas o retorno financeiro também era considerado pelos autores. A postura de interferência do editor justifica-se porque, sobretudo, cabia a ele garantir a venda do livro.

A análise dos contratos entre Francisco Alves e seus autores feita por Aníbal Bragança mostra diferentes formas de pagamento dos textos e expressa a existência de variadas maneiras de apropriações das edições subseqüentes pelos editores:

Os editores, por escritura de 05.01.1900, adquiriram ao autor, a "propriedade plena" des- 
tes dois livros, pagando a Thomaz Galhardo 9:000\$000. em $12(1+11)$ prestações mensais de 750\$000." (1999, p. 465)

Conceição Cabrini em seu estudo sobre Felisberto de Carvalho fornece ainda importantes dados sobre as interferências do editor no texto. 0 poder de modificar, ampliar, incluir imagens, entre outras formas de intervenção do editor no texto do autor dependia do contrato. Uma cláusula do contrato assinado entre Felisberto de Carvalho e Francisco Alves mostra, por exemplo, que o

Quinto Livro de Leitura, com cerca de 450 páginas, em 16, francez foi comprada pela quantia de dez contos e 500 mil réis (...) podendo os outorgados dispor inteira e exclusivamente o livro para fazer tantas edições quantas lhes convenham, sobre o formato e título que julgarem convenientes, podendo mesmo resumir, vir aumentar o livro em futuras edições, vir juntá-los, vir reuni-los a outros trabalhos. (1993, p. 68)

Outros contratos garantiam menor intervenção do editor na obra, sobretudo no caso do autor assumir parte dos custos e, neste caso, o preço do livro e a porcentagem do autor eram diferentes. Os direitos do autor sobre a própria obra tinham assim variações.

A editora Francisco Alves acompanhou as inovações tecnológicas na fabricação dos livros, mantendo associações com empresas editoriais no exterior, sobretudo, para garantir impressões com menor custo. A visão empresarial do editor possibilitava colocar o livro no mercado a preços mais baixos, facilitando sua difusão e possibilitando uma "longa vida" para muitos dos seus best-sellers. Considerando esta outra importante característica do livro didático - o grande número de reedições - pode-se entender também o poder de interferência maior do editor nas adaptações e renovações da obra.

0 comportamento dos professores em relação ao livro didático tem sido bastante con- traditório desde esse periodo. Exigem obras atualizadas, mas ao mesmo tempo desconfiam das renovações pedagógicas que alteram a configuração do saber escolar, tanto nos conteúdos quanto nos métodos de ensino. Daí o cuidado dos editores em oferecer uma obra aparentemente nova (capa, certas ilustrações, títulos), mas sem mudar efetivamente o conteúdo.

Um número significativo de obras produzidas no final do século XIX e início do século XX teve inúmeras edições e foram usadas por várias gerações de alunos. Além das obras da editora Francisco Alves, que encabeçaram as listas de livros aprovados e adotados nas escolas primárias e secundárias oficiais até 1920, livros de outras editoras, especialmente as destinadas às escolas confessionais, também tiveram "uma longa duração". O catálogo da Casa Briguiet de 1936 traz livros de Joaquim Maria de Lacerda, um autor religioso de variadas obras para o ensino elementar produzidas na década de 1880. 0 falecimento do autor não diminuiu a venda de suas obras, conforme atestam os catálogos que indicam as "atualizações" realizadas por outro autor em seus textos originais. A permanência dessas obras comprova a importância da "tradição escolar" e o alcance das mudanças às quais autores e editores estavam ou ainda estão submetidos, no processo de reformulações curriculares.

A trajetória de produção dos primeiros autores brasileiros possibilita identificar algumas das características das relações entre autor, editor e Estado. Permite constatar as especificidades do texto didático e a complexa teia de interferências a que o livro é submetido. Esses primeiros autores, com maior ou menor autonomia, foram os criadores de textos didáticos que possibilitaram a configuração de uma produção nacional, com características próprias. Mesmo que a forma se assemelhasse aos livros estrangeiros, os textos escolares expressaram uma produção própria que buscava atender as condições de trabalho dos professores das escolas públicas que se espalhavam pelo país. Procuravam suprir a ausência de formação dos docentes, em sua 
grande maioria leigos e autodidatas.

Os editores sempre estiveram atentos a essas especificidades. 0 interesse comercial, entretanto, nunca saiu do horizonte de seu ideal de promotor da cultura letrada. B. L. Garnier, editor responsável pela publicação de várias obras da literatura nacional, como as José de Alencar e Machado de Assis, afirmava que o livro didático era "a carne" da produção editorial em contraposição às obras de literatura ou "científicas" que corresponderiam aos "ossos".

A comercialização do livro didático, no entanto, sempre esteve dependente do Estado, quer pelo seu poder de aprovação quer como comprador, condição que conduziu os editores a estratégias diversas de aproximação com o poder educacional. Uma delas era assegurar a presença de autores que estivessem de alguma forma pró- ximos ao poder. Perceberam, entretanto, que nem sempre a figura dos "sábios", conforme preconizava a elite governamental, garantia um texto didático de "qualidade”. Experiência didática é um fator importante e daí a preferência dos editores por professores e certa desconfiança em relação aos intelectuais renomados.

A história dos autores de obras didáticas possibilita uma maior reflexão sobre a função do autor nessa produção específica e bastante diversa dos demais livros. 0 problema da autoria da obra didática não é recente, confluindo em sua confecção muitos sujeitos. A história do livro didático mostra as mudanças quanto ao grau de interferência entre os diversos sujeitos assim como as mudanças das políticas educacionais em relação a esse significativo objeto cultural, símbolo da escola moderna.

\section{Referências bibliográficas}

ALMEIDA, R. P. de L'instruccion publique au Brésil: histoire et législation. Rio de Janeiro: Imp. Leuzinger \& Filhos, 1889.

BITTENCOURT, C. M. F. Livro didático e conhecimento histórico: uma história do saber escolar. 1993. Tese (Doutorado)Faculdade de Filosofia, Letras e Ciências Humanas da Universidade de São Paulo, São Paulo, 1993. 369p.

BRAGANÇA, A. A política editorial de Francisco Alves e a profissionalização do escritor no Brasil. In: ABREU, M. (Org.). Leitura, história e história da leitura. São Paulo: Fapesp, 1999. p. 451-476.

CABRINI, C. Memória do livro didático: os livros de leitura de Felisberto Rodrigues Pereira de Carvalho. 1994. Dissertação (Mestrado)- Escola de Comunicação e Arte da Universidade de São Paulo, São Paulo, 1994, 135p.

CARVALHO, F. R. P. de Dicionário gramatical. Rio de Janeiro: B. L. Garnier, 1886.

CATARSI, E. Un cuore che ha cento anni: e quello di De Amicis. Bollettino CIRSE, 1896, n. 12, p. 31-35.

CHARTIER, R. A história cultural: entre práticas e representações. Tradução de Maria Manuela Galhardo. Lisboa: DIFEL; Rio de Janeiro: Agir, 1970.

A ordem dos livros. Lisboa: Passagens, 1997.

DUPUY, A. Les livres de lectures de G. Bruno. Revue D'histoire Économique et Sociale, Paris, n. 20, 1953.

FOUCAULT, Michel Qu'est-ce un auteur? Littoral, Paris, n. 9, 1983, p. 73-104.

GASPARELLO, A. M. Construtores de identidades: a pedagogia da nação nos livros didáticos da escola secundária brasileira. São Paulo: Iglu, 2004.

HALLEWELL, L. 0 livro no Brasil (sua história).São Paulo: T. A. Queirós/ EDUSP, 1985.

KÖPKE, J. A leitura analítica. São Paulo: Tipografia Hennies Irmãos, 1896. 
LAJOLO, M. Usos e abusos da literatura na escola: Bilac e a literatura escolar na República Velha. Rio de Janeiro: Globo, 1982.

LISBOA, J. da S. Visconde de Cairu: escola brasileira ou instrução útil a todas as classes extraída da sagrada escritura para a mocidade. Rio de Janeiro: Tipografia Plancher-Seignot, 1827.

NORA, P. Lavisse, instituteur national. In: NORA, P. (Dir.) Les lieux de mémoire. Paris: Gallimard, p. 291-322, 1984. (Tome I: La République)

PARANAGUÁ, M. de Elementos de geometria. 5. ed. Rio de Janeiro: Typografia Universal de Læmmert, 1846.

PFROMM NETO, S. et al. 0 livro na educação. Rio de Janeiro: Primor, INL, 1974.

PINHEIRO, M. P. F. Apresentação à $3^{\mathbf{a}}$ edição do curso de literatura nacional do cônego Fernandes Pinheiro. Rio de Janeiro: Livraria Editora Cátedra, 1978.

POMPÉIA, R. 0 Ateneu (crônica de saudades). Rio de Janeiro: Francisco Alves \& Cia., 1905.

ROCHA, J. J. da História Antiga. Rio de Janeiro: Typographia do Regenerador de J. Rocha, 1860.

SCHWARCZ, L. M. Os guardiões da nossa história oficial. São Paulo: Idesp, 1989.

SIEPE, Hans T. L'imaginaire historique. Histoire Historiographie, Paris, n. 14, 1988, p. 160-177.

VIEIRA, M. Treze anos de magistério no Rio de Janeiro: 1875 a 1887. Rio de Janeiro: Læmmert \& Cia., 1887.

Recebido em 07.10.04

Aprovado em 03.11.04

Circe Maria F. Bitencourt é professora doutora do Programa de Pós-Graduação da Faculdade de Educação da USP e doutora em História Social pela Faculdade de Filosofia Ciências e Letras da USP. 